\title{
LEVANTAMENTO FLORÍSTICO DE UM FRAGMENTO DE FLORESTA OMBRÓFILA MISTA ALUVIAL DO RIO IGUAÇU, MUNICÍPIO DE PALMEIRA (PR)
}

\author{
Mariângela Ceschim Iurk ${ }^{1}$, Elide Pereira dos Santos ${ }^{2}$, Fernando Luís Dlugosz ${ }^{3}$, \\ Rosângela Capuano Tardivo ${ }^{4}$ \\ ${ }^{1}$ Bióloga, M.Sc., Curitiba, PR, Brasil - mciurk@yahoo.com.br \\ ${ }^{2}$ Bióloga, Dr ${ }^{\mathrm{a}}$., Depto. de Botânica, UFPR, Curitiba, PR, Brasil - elide@ufpr.br \\ ${ }^{3}$ Eng. Florestal, M.Sc., Doutorando em Engenharia Florestal, UFPR, Curitiba, PR, Brasil - f.dlugosz@ gmail.com \\ ${ }^{4}$ Bióloga, Dr ${ }^{\mathrm{a}}$., Depto. de Biologia, UEPG, Ponta Grossa, PR, Brasil - rc.tardivo@uol.com.br \\ Recebido para publicação: 16/04/2008 - Aceito para publicação: 28/10/2008
}

\begin{abstract}
Resumo
No período entre fevereiro de 2006 e novembro de 2007, realizou-se o levantamento florístico de um fragmento de Floresta Ombrófila Mista Aluvial à margem do rio Iguaçu, no município de Palmeira (PR). Espera-se, dessa maneira, contribuir para o conhecimento da flora do Paraná e gerar subsídios para futuros estudos de preservação e recuperação de florestas aluviais. Para tanto, foram alocadas duas parcelas, totalizando aproximadamente 2,5 ha. As coletas de material botânico foram mensais, e, para a determinação das espécies, empregou-se bibliografia específica, eventuais consultas a especialistas e comparações com exsicatas tombadas em herbários da região. A floresta apresentou-se estruturada em três estratos. Coletaram-se indivíduos distribuídos em 67 famílias, 111 gêneros e 134 espécies. As famílias que se destacaram em número de espécies foram Myrtaceae, Asteraceae, Solanaceae, Cyperaceae, Rubiaceae, Bromeliaceae e Poaceae. Muitas das espécies identificadas estavam presentes em outros estudos realizados em ambiente similar, indicando que os resultados são representativos.
\end{abstract}

Palavras-chave: Floresta Ombrófila Mista Aluvial; levantamento florístico; rio Iguaçu.

\begin{abstract}
Floristic survey of one break up of Forest Ombrophylous Mixed Aluvial the Iguaçu river, Palmeira City (PR). During the period from February, 2006 to November 2007, it was developed a survey about a flowering fragment of the Ombrophylous Mixed Aluvial forest in the bank of Iguaçu River in the city of Palmeira (PR). One expects, in this way, to contribute for the knowledge of the Flora of the Paraná and to generate subsidies for future studies of preservation and recovery of aluvial forests. To get to this result it was analyzed two plots that added about 2,5 ha. The collections of botanical materials were monthly, and for the determination of the species specific bibliography it was used, eventual consultations to specialists and comparisons with registered exsiccates in herbaria of the region. The forest was presented structuralized in three stratus. Individuals distributed in 67 families, 111 genera and 134 species had collected themselves. The families which had detached in species number were Myrtaceae, Asteraceae, Solanaceae, Cyperaceae, Rubiaceae, Bromeliaceae and Poaceae. Many of the identified species were found in other studies carried out in similar environment, indicating that the results are representative.

Keywords: Mixed ombrophilous forest; aluvial; forest flowering survey; Iguaçu river.
\end{abstract}

\section{INTRODUÇÃO}

O rio Iguaçu é o maior rio totalmente paranaense. Tem suas nascentes na frente ocidental da Serra do Mar e percorre no sentido leste-oeste 910 quilômetros, perfazendo a maior bacia hidrográfica do estado, com uma área total equivalente a $70.800 \mathrm{~km}^{2}$, com seus tributários drenando terras pertencentes aos estados do Paraná e Santa Catarina. Considerando apenas as terras paranaenses, a bacia possui 57.329 $\mathrm{km}^{2}$. Trata-se de um dos afluentes da margem esquerda do rio Paraná, e nos Campos Gerais tem caráter 
antecedente, provindo do Primeiro Planalto Paranaense a leste, atravessando a Escarpa Devoniana através de vale encaixado. Desenvolve planícies aluviais extensas, mas descontínuas. Seu principal afluente é o rio Negro, que também nasce na Serra do Mar, e encontra o Iguaçu $240 \mathrm{~km}$ depois (MAACK, 2002).

De forma geral, florestas aluviais são definidas como formações arbóreas encontradas nos taludes, superfícies de inundação e áreas adjacentes de rios, córregos, lagos ou represas, com drenagem bem definida ou mesmo difusa (REICHARDT, 1989; LIMA, 1989; STEVENS et al., 1995; RODRIGUES, 2001). Constituem manchas de vegetação caracterizadas pela combinação diferenciada da atuação de fatores abióticos que resultam em trechos florestais com florística e estrutura própria (RODRIGUES, 1989).

Os ambientes aluviais encontram-se distribuídos pelas mais diferentes áreas do país - de Roraima ao Rio Grande do Sul - apresentando as mais notáveis composições de biodiversidade (AB'SABER, 2001). Esses ambientes refletem as características geológicas, climáticas, hidrológicas e hidrográficas, que atuam como elementos definidores da paisagem e, portanto das condições ecológicas locais (RODRIGUES; SHEPHERD, 2001).

O termo Floresta Ombrófila Mista Aluvial é uma denominação proposta por Veloso et al. (1991) para designar trechos de Floresta Ombrófila Mista que ocupam os terrenos aluvionares situados nos flúvios das serras costeiras voltadas para o interior ou nos planaltos dominados pela Araucaria angustifolia associada a ecotipos que variam de acordo com a altitude dos flúvios, percorrendo terreno de geomorfia plana até suave ondulado. É uma formação caracterizada por um pequeno número de espécies seletivas, adaptadas a se desenvolver nos solos altamente higromórficos e sujeitos a periódicas enchentes, existentes ao longo dos rios do planalto sul brasileiro (KLEIN, 1984).

Apesar dessas formações serem protegidas por lei, continuam sendo intensamente devastadas, seja para retirada de madeira, seja para exploração agropecuária ou simplesmente por ação antrópica indiscriminada (RODRIGUES e GANDOLFI, 2001; AB'SABER, 2001). A vegetação, principalmente a arbórea, foi extraída para servir de combustível às embarcações a vapor em regiões de ocorrência de rios navegáveis. Os remanescentes constituem hoje, segundo Borghi et al. (2004), apenas um mosaico de fragmentos aluviais situados em locais de topografia acidentada.

O Código Florestal (Lei n. ${ }^{\circ}$ 777/65) inclui as florestas aluviais na categoria de áreas de preservação permanente. Assim, toda a vegetação natural (arbórea ou não) presente ao longo das margens dos rios e ao redor de nascentes e de reservatórios deve ser preservada.

Atualmente, a legislação vigente impõe a preservação e a recuperação desses ambientes. A realização de levantamentos florísticos torna-se importante para o conhecimento das espécies presentes, fornecendo informações básicas para a execução de estudos mais detalhados sobre a vegetação (VAN DEN BERG, 1995), além de servir de base para trabalhos de recuperação de áreas degradadas em situações similares.

Embora tenham sido desenvolvidos alguns trabalhos em Floresta Ombrófila Mista Aluvial em toda a extensão do rio Iguaçu, como Pasdiora (2003), Barddal et al. (2003b), Bonnet (2006), Curcio (2006) e Iurk et al. (2007), não foram registradas publicações na região de Palmeira.

Segundo Felfili; Silva-Júnior (1992), levantamentos florísticos e fitossociológicos contribuem com informações adequadas para a elaboração e planejamento de ações que visam a preservação da vegetação regional, conservando o máximo da diversidade local.

Em vista disso, o presente trabalho realizou o levantamento florístico de um remanescente de Floresta Ombrófila Mista Aluvial, com o objetivo de identificar as espécies que ocorrem na região, elaborando uma lista que contribuirá para o conhecimento da flora do Paraná, além de subsidiar estudos futuros da vegetação natural.

\section{MATERIAL E MÉTODOS}

\section{Localização e caracterização da área de estudo}

A área de estudo compreende um remanescente de vegetação aluvial, localizado à margem do rio Iguaçu (2536'11,9'S e 5001'33,9”W), na comunidade de Três Morros, município de Palmeira (PR), distante linearmente $20 \mathrm{~km}$ da sede do município (Figura 1).

A área de estudo está inserida na APA da Escarpa Devoniana, instaurada através do Decreto Estadual $\mathrm{n}^{\circ} 1.231$, de 27 de março de 1992, ocupando uma extensão de aproximadamente 392.363 ha. O 
decreto estabelece como seu objetivo principal "assegurar a proteção do limite natural entre o Primeiro e o Segundo Planalto Paranaense, inclusive a faixa de Campos Gerais, que constituem ecossistema peculiar que alterna capões da Floresta com Araucária, matas de galerias e afloramentos rochosos, além de locais de beleza cênica, como os canyons, e de vestígios arqueológicos e pré-históricos".

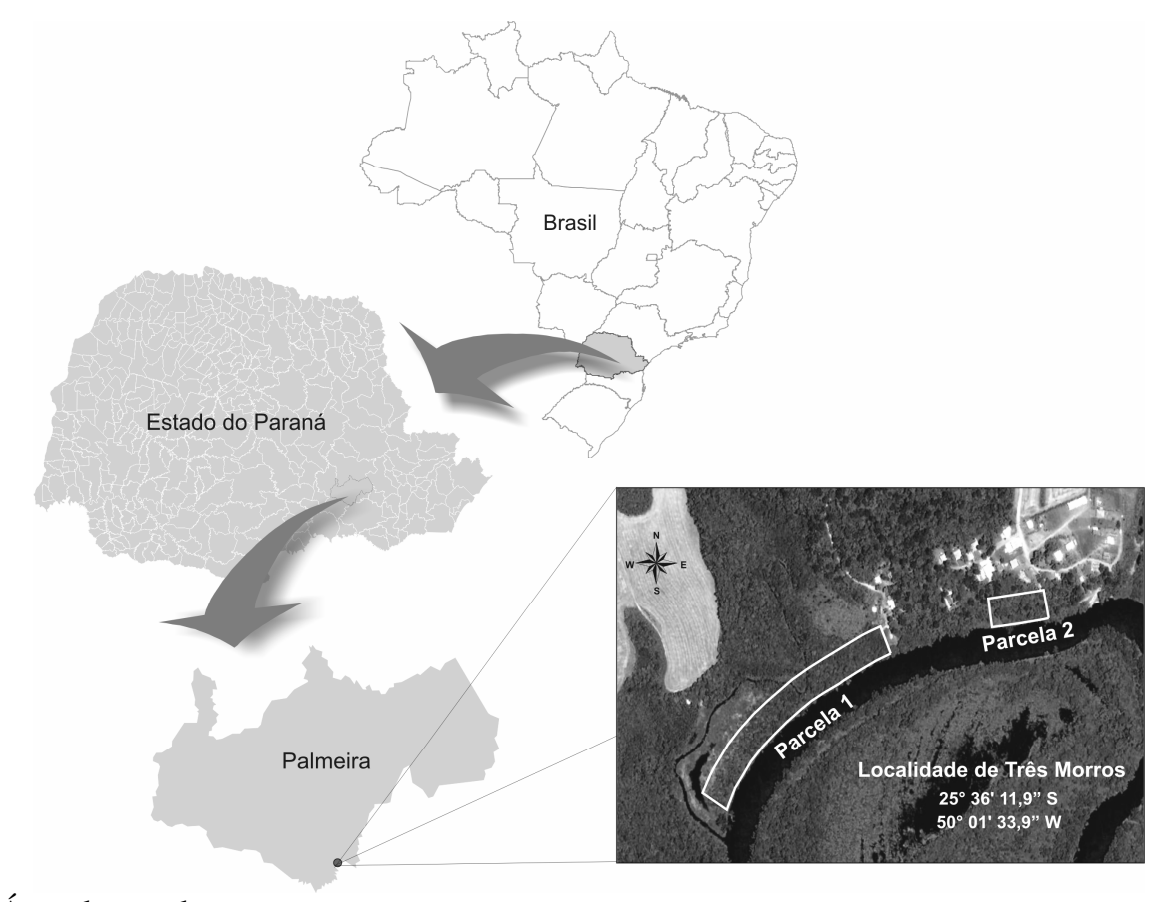

Figura 1. Área de estudo.

Figure 1. Study área.

O trabalho foi executado em duas propriedades contíguas, sendo uma com 208 ha e a outra de 49 ha, que apresentaram remanescente de floresta aluvial melhor conservado quanto as suas características naturais, não devido à sua condição de área de preservação legal, mas sim pelo fato da inexistência da criação de bovinos na área, fator comumente encontrado nas propriedades locais e responsável pela compactação do solo e destruição da vegetação de sub-bosque.

A vegetação constitui-se fitofisionomicamente por formação arbórea, classificada pelo IBGE (1992) como Floresta Ombrófila Mista Aluvial. Apresenta também, de entremeio a essa formação, uma vegetação de caráter herbáceo-arbustivo, denominada, segundo a mesma classificação, de Formação Pioneira com Influência Fluvial, ambas inseridas na grande região da Estepe Gramíneo-Lenhosa do Sul do Brasil, denominada localmente como Campos Gerais. A altitude é de aproximadamente 780 m.s.n.m., com relevo suavemente ondulado, de origem erosiva (MELO; MENEGUZO, 2001).

O clima regional, segundo a classificação de Köppen, é Cfb - temperado, apresentando verões frescos, com temperatura média inferior de $22{ }^{\circ} \mathrm{C}$ e invernos severos, com temperatura média inferior a $18^{\circ} \mathrm{C}$ no mês mais frio e ocorrência de geadas frequentes (MAACK, 2002). Possui chuvas bem distribuídas ao longo do ano, o que determina uma umidade relativa do ar média em torno de $85 \%$ e precipitação em torno de $1.400 \mathrm{~mm}$ anuais (MELO et al.).

Localiza-se no flanco oriental da Bacia do Paraná, onde esta é profundamente afetada pelo Arco de Ponta Grossa, ocorrendo rochas sedimentares cenozoicas (MELO et al.). Nessa região, o rio Iguaçu tem caráter antecedente. Provém do Primeiro Planalto Paranaense a leste e atravessa a Escarpa Devoniana através de vale encaixado, desenvolvendo uma planície aluvial extensa.

Para a área estudada, dois tipos de solos foram encontrados. Nas porções mais elevadas e de melhor drenagem, o solo é classificado como Cambissolo Húmico distrófico típico e léptico, fase argilosa, relevo ondulado, substrato argilito. Nas baixadas, Gleissolo Háplico distrófico típico, A moderado, textura argilosa, relevo plano e suave ondulado. 


\section{Levantamento florístico}

Para efetuar os estudos foram demarcadas duas parcelas, uma de 50x400 m, denominada Parcela 1, e outra de 50×100 m, denominada Parcela 2, conforme diferenciação da compartimentação pedológica. Essas áreas foram alocadas ao longo da margem direita do rio (sentido nascente-foz), totalizando aproximadamente 2,5 ha.

Os trabalhos de campo foram realizados entre fevereiro de 2006 e novembro de 2007, coletandose nesse período todos os fanerógamos férteis encontrados nas parcelas. Para tanto, utilizou-se tesoura de poda alta com cabo telescópico ("podão") ou tesoura de poda manual, através de escalada nas árvores ou diretamente do chão. Em ficha de campo foram registradas informações dendrométricas referentes ao CAP, altura total estimada (para os indivíduos arbóreos), além de data de coleta e outras observações relacionadas à época de florescimento e frutificação. Com base nos dados de altura estimada, observou-se o comportamento das espécies, verificando-se na floresta a formação dos estratos: inferior, médio e superior (dossel).

Os exemplares coletados foram preparados de acordo com a metodologia usual (FIDALGO e BONONI, 1989) e determinados com o auxílio de chaves analíticas e comparação direta com exsicatas tombadas nos Herbários UPCB, MBM e HUPG, além de consultas a especialistas.

A classificação das espécies conforme os tipos biológicos foi realizada com base em Whittaker (1975) apud Matteucci; Colma (1982), inserindo-se algumas modificações. Foram acrescidos aos tipos biológicos propostos (arbóreo, arbustivo e herbáceo) os epífitos e escandentes.

Para o nome dos autores das espécies, foram adotadas as abreviaturas propostas por Brummtii e Powel (1992), e para a verificação da validade dos nomes científicos das espécies utilizou-se o International Plant Name Index. Os problemas encontrados por ocasião da consulta em ambos os trabalhos mencionados foram solucionados através de literatura específica. O sistema de classificação seguido para a apresentação da listagem das espécies foi o APG II (2003).

Para facilitar a compreensão das peculiaridades florísticas e estruturais de áreas de Floresta Ombrófila Mista Aluvial que ocorrem ao longo do rio Iguaçu, elaborou-se uma comparação com outros estudos realizados nesses ambientes.

\section{RESULTADOS E DISCUSSÃO}

No presente levantamento foram coletados 318 indivíduos, distribuídos em 67 famílias, 111 gêneros e 134 espécies, compreendendo indivíduos de todos os tipos biológicos considerados para a classificação das espécies. As famílias que mais se destacaram em número de espécies foram Myrtaceae (13), Asteraceae (13), Solanaceae (9), Cyperaceae (6), Rubiaceae (6), Bromeliaceae (5) e Poaceae (5). A figura 2 ilustra essa situação.

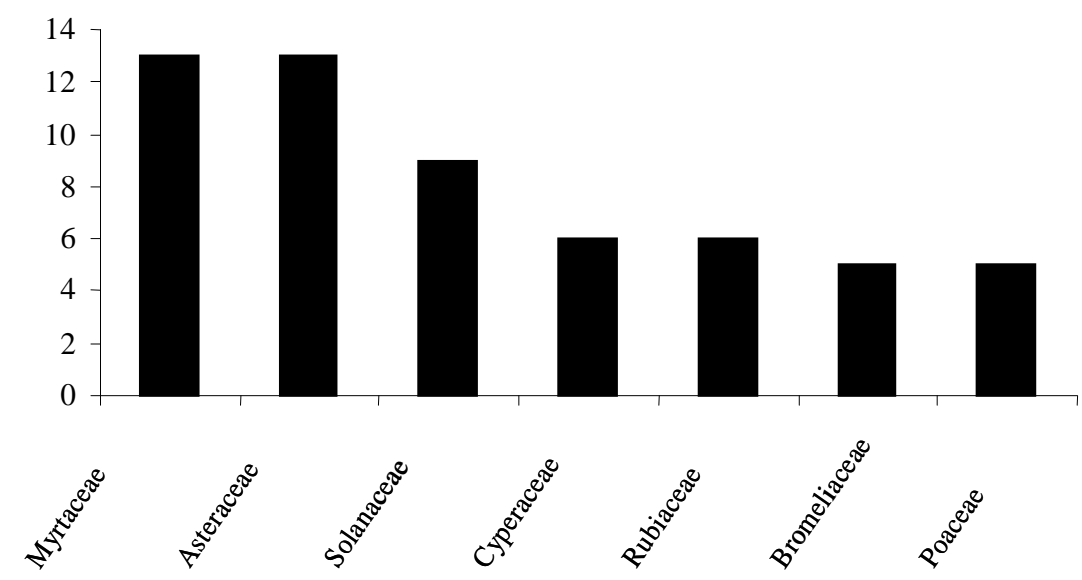

Figura 2. Famílias com maior número de espécies coletadas em floresta aluvial do rio Iguaçu. Figure 2. Families with higher number of species collected in aluvial forest of the Iguaçu river. 
Segundo Durigan et al. (2001), é característica dos ambientes aluviais a heterogeneidade florística e estrutural. Pode-se afirmar que dentro de um mesmo domínio morfoclimático, numa área delimitada por condições geográficas, climáticas e edáficas específicas, os remanescentes da vegetação florestal que acompanham os cursos d'água apresentam características em comum.

A tabela 1 mostra a relação das espécies levantadas, apresentadas com os seus respectivos meses de coleta do material com flores e/ou frutos por espécie, tipo biológico, amplitude em CAP e altura total.

Tabela 1. Relação das famílias e espécies coletadas na floresta aluvial do rio Iguaçu, com seus respectivos tipos biológicos (TB - AV: Arbóreo; AB: Arbustivo; HE: Herbáceo; EP: Epífito; ES: Escandente), mês em que o material foi coletado com flores (FL) e/ou frutos (FR), amplitude em CAP e altura total (h). (*) espécies que ainda não foram coletadas férteis.

Table 1. Relation of the families and species collected in the aluvial forest of the Iguaçu river, with its respective biological types (TB - AV: tree; AB: shrub; HE: Herb; EP: epiphytes; ES: liane), month where the material was collected with flowers (FL) and/or fruits (FR), amplitude in CAP and total height $(\mathrm{h}) .\left(^{*}\right)$ species that had still not been collected fertile.

\begin{tabular}{|c|c|c|c|c|c|c|c|}
\hline \multirow{2}{*}{$\begin{array}{l}\text { Famílias } \\
\text { Espécies }\end{array}$} & \multirow{2}{*}{ TB } & \multicolumn{2}{|c|}{ Mês de coleta } & \multicolumn{2}{|c|}{ CAP } & \multicolumn{2}{|c|}{$\mathbf{h}$} \\
\hline & & Fl & Fr & Min. & Máx. & Min. & Máx. \\
\hline ACANTHACEAE & & & & & & & \\
\hline $\begin{array}{l}\text { Hygrophila costata Sinning } \\
\text { AMARANTHACEAE }\end{array}$ & $\mathrm{HE}$ & 08 & - & - & - & - & - \\
\hline Alternanthera philoxeroides Griseb. & $\mathrm{HE}$ & 11,12 & _ & _ & _ & _ & _ \\
\hline Alternanthera tenella Colla & $\mathrm{HE}$ & 06 & - & - & - & - & - \\
\hline $\begin{array}{l}\text { Pfaffia glomerata (Spreng.) Pedersen } \\
\text { ANACARDIACEAE }\end{array}$ & $\mathrm{HE}$ & $06,11,12$ & - & - & - & - & - \\
\hline Lithraea brasiliensis Marchand* & $\mathrm{AV}$ & - & - & 51,3 & 104,5 & 10 & 16 \\
\hline $\begin{array}{l}\text { Schinus terebinthifolius Raddi } \\
\text { AQUIFOLIACEAE }\end{array}$ & $\mathrm{AV}$ & 11,12 & 04,12 & 35,7 & 87,0 & 6 & 15 \\
\hline $\begin{array}{l}\text { Ilex theezans Mart.* } \\
\text { ARAUCARIACEAE }\end{array}$ & $\mathrm{AV}$ & - & - & 34,3 & 59,2 & 9 & 12 \\
\hline $\begin{array}{l}\text { Araucaria angustifolia (Bert.) O. Kuntze } \\
\text { ARECACEAE }\end{array}$ & $\mathrm{AV}$ & - & 07 & 166,5 & 176,5 & 11 & 25 \\
\hline $\begin{array}{l}\text { Syagrus romanzoffiana (Cham.) } \\
\text { Glassman* } \\
\text { APOCYNACEAE }\end{array}$ & $\mathrm{AV}$ & 12 & - & 38,0 & 97,8 & 5 & 15 \\
\hline $\begin{array}{l}\text { Orthosia urceolata E. Fourn. } \\
\text { ASTERACEAE }\end{array}$ & $\mathrm{HE}$ & $06,07,08,11$ & 07 & - & - & - & - \\
\hline Ageratum conyzoides $\mathrm{L}$. & $\mathrm{HE}$ & 06 & - & - & - & - & - \\
\hline Baccharis brachylaenoides DC. & $\mathrm{AV}$ & 07,08 & - & - & - & - & 5 \\
\hline Bidens pilosa $\mathrm{L}$. & HE & 06,12 & 06,12 & - & - & - & - \\
\hline Calyptocarpus biaristatus (DC.) H. Rob. & $\mathrm{HE}$ & 08 & - & - & - & - & - \\
\hline Chaptalia nutans (L.) Polak & $\mathrm{HE}$ & $07,08,09$ & 11 & - & - & - & - \\
\hline Coniza bonariensis (L.) Conquist & $\mathrm{HE}$ & $10,11,12$ & - & - & - & - & - \\
\hline Elephantopus mollis Kunth & $\mathrm{HE}$ & 07 & - & - & - & - & - \\
\hline Emilia sonchifolia (L.) DC. & $\mathrm{HE}$ & 06 & - & - & - & - & - \\
\hline Gnaphalium gaudichaudianum DC. & ES & 11 & - & - & - & - & - \\
\hline Gochnatia polymorpha (Less.) Cabrera & $\mathrm{AV}$ & - & - & - & 55,5 & - & 14 \\
\hline Mikania micrantha Kunth & ES & 04,12 & - & - & - & - & - \\
\hline $\begin{array}{l}\text { Podocoma notobellidiastrum (Griseb.) G. } \\
\text { L. Nesom }\end{array}$ & $\mathrm{HE}$ & 08,09 & 11 & - & - & - & - \\
\hline $\begin{array}{l}\text { Senecio brasiliensis (Spreng.) Less. } \\
\text { BEGONIACEAE }\end{array}$ & $\mathrm{HE}$ & 11 & - & - & - & - & - \\
\hline Begonia cucullata Ruiz ex A. DC. & $\mathrm{HE}$ & 01 & - & - & - & - & - \\
\hline
\end{tabular}


Aechmea recurvata (Klotzsch) L. B. Sm.

EP $\quad 08$

Platyaechmea distichantha (Lemaire) L. $\quad$ EP 06

B. Sm. \& W. J. Kress

Tillandsia tenuifolia $\mathrm{L}$.

Tillandsia usneoides (L.) L.

Vriesea friburgensis Mez

CACTACEAE

Lepismium warmingianum (Schum.)

Barthlott

Rhipsalis cereuscula Haw. ex Phil.

Rhipsalis floccosa Salm-Dyck ex Pfeiff.

Capsicodendron dinisii (Schwacke)

Occhioni

\section{CELASTRACEAE}

Maytenus ilicifolia Mart. ex Reissek*

Commelina erecta $\mathrm{L}$.

Tradescantia fluminensis Velloso

CONVOLVULACEAE

Ipomoea cairica (L.) Sweet*

Ipomoea indivisa Hallier

CUCURBITACEAE

Cayaponia bonariensis (Mill.)

Mart.Crov.

CYPERACEAE

Carex brasiliensis St.-Hil.

Cyperus giganteus Vahl

Cyperus luzulae Hochst. ex Steud.

Cyperus virens Boeckeler

Rhynchospora splendens Lindm.

CYPERACEAE

Scleria latifolia $\mathrm{Sw}$.

EUPHORBIACEAE

Bernardia pulchella Müll. Arg.

Sebastiania commersoniana (Baillon) L.

B. Sm. \& R. J. Downs

Tragia volubilis $\mathrm{L}$.

FABACEAE - MIMOSOIDEAE

Acacia recurva Benth.

Calliandra brevipes Benth.

GESNERIACEAE

Sinningia douglasii (Lindl.) Chautems

HYPERICACEAE

Hypericum brasiliense Choisy

Hypericum carinatum Griseb.

LAMIACEAE

Leonurus sibiricus L.***

Vitex megapotamica (Spreng.) Moldenke

LAURACEAE

Cinnamomum amoenum (Nees)

Kosterm.*

Cinnamomum sellowianum (Nees \&

Mart.) Kosterm.*

Nectandra grandiflora Nees \& Martius

Nectandra membranacea (Swartz)

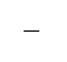




\begin{tabular}{|c|c|c|c|c|c|c|c|}
\hline Grisebach* & & & & & & & \\
\hline $\begin{array}{l}\text { Ocotea pulchella Mart.* } \\
\text { MALPIGHIACEAE }\end{array}$ & AV & - & - & - & 57,0 & - & 10 \\
\hline $\begin{array}{l}\text { Heteropteris martiana A. Juss. } \\
\text { MALVACEAE }\end{array}$ & ES & 04 & - & - & - & - & - \\
\hline Hibiscus selloi Gürke & $\mathrm{HE}$ & 12 & - & - & - & - & - \\
\hline Luehea divaricata Mart. & AV & 12 & 04,06 & 12,2 & 150,0 & 10 & 16 \\
\hline $\begin{array}{l}\text { Pavonia sepium A. St.-Hil. } \\
\text { MELASTOMATACEAE }\end{array}$ & HE & 08 & - & - & - & - & - \\
\hline Leandra australis Cogn. & HE & 09 & - & - & - & - & - \\
\hline Leandra carassana Cogn. & $\mathrm{AB}$ & 08 & - & - & - & - & - \\
\hline $\begin{array}{l}\text { Miconia cinerascens Miq. } \\
\text { MONIMIACEAE }\end{array}$ & AV & 08,11 & - & 28,0 & 49,8 & 4 & 8 \\
\hline $\begin{array}{l}\text { Mollinedia clavigera Tul. } \\
\text { MORACEAE }\end{array}$ & $\mathrm{AB}$ & 09 & - & - & - & - & - \\
\hline $\begin{array}{l}\text { Morus nigra } \text { L.* } \\
\text { MYRSINACEAE }\end{array}$ & ES & - & - & - & - & - & - \\
\hline $\begin{array}{l}\text { Myrsine coriacea (Sw.) R. Br. ex Roem } \\
\text { \& Schult. }\end{array}$ & AV & 08 & - & 20,4 & 38,5 & 3 & 9 \\
\hline $\begin{array}{l}\text { Myrsine parvula (Mez) M. Otegui } \\
\text { MYRTACEAE }\end{array}$ & AV & 09 & - & - & - & - & 4 \\
\hline Calyptranthes concinna DC. & AV & 11,12 & $01,08,12$ & 16,0 & 60,3 & 5 & 14 \\
\hline Campomanesia xanthocarpa O. Berg* & AV & - & - & - & 33,5 & - & 12 \\
\hline Eugenia handroana D. Legr.* & AV & - & - & - & 22,5 & - & 7 \\
\hline Eugenia hyemalis Cambess. & AV & 04,11 & 08 & 16,8 & 50,0 & 4 & 10 \\
\hline Gomidesia palustris (DC.) D. Legr.* & $\mathrm{AV}$ & - & - & 28,6 & 45,8 & 10 & 12 \\
\hline Gomidesia sellowiana $\mathrm{O}$. Berg* & $\mathrm{AV}$ & - & - & - & 99,0 & - & 12 \\
\hline Myrcia laruotteana Cambess. & $\mathrm{AB}$ & 09 & - & - & - & - & - \\
\hline Myrcia multiflora DC. & AV & 11 & - & 17,5 & 49,3 & 7 & 12 \\
\hline Myrcia obtecta Kiaersk.* & AV & - & - & 19,5 & 31,0 & 3 & 5 \\
\hline Myrcianthes gigantea D. Legr.* & AV & - & - & - & 32,0 & - & 5 \\
\hline Myrciaria tenella (DC.) O. Berg & AV & 01,10 & - & 18,0 & 24,0 & 5 & 8 \\
\hline Myrceugenia ovata $\mathrm{O}$. Berg & AV & 12 & - & 17,8 & 32,0 & 3 & 10 \\
\hline $\begin{array}{l}\text { Psidium cattleianum Sabine } \\
\text { ONAGRACEAE }\end{array}$ & AV & 11 & - & - & 52,4 & - & 10 \\
\hline Ludwigia elegans (Cambess.) H. Hara & HE & 12 & - & - & - & - & - \\
\hline $\begin{array}{l}\text { Ludwigia peruviana (L.) H. Hara } \\
\text { ORCHIDACEAE }\end{array}$ & HE & 03 & - & - & - & - & - \\
\hline Capanemia micromera Barb. Rodr. & $\mathrm{EP}$ & 08 & - & - & - & - & - \\
\hline $\begin{array}{l}\text { Leptotes unicolor Barb. Rodr. } \\
\text { OXALIDACEAE }\end{array}$ & $\mathrm{EP}$ & 06 & - & - & - & - & - \\
\hline $\begin{array}{l}\text { Oxalis bipartita A. St.-Hil. } \\
\text { PASSIFLORACEAE }\end{array}$ & $\mathrm{HE}$ & 09 & - & - & - & - & - \\
\hline $\begin{array}{l}\text { Passiflora misera Kunth } \\
\text { PHYLLANTHACEAE }\end{array}$ & ES & 12 & - & - & - & - & - \\
\hline Phyllanthus caroliniensis Walter & HE & 08 & - & - & - & - & - \\
\hline $\begin{array}{l}\text { Phyllanthus niruri L. } \\
\text { PLANTAGINACEAE }\end{array}$ & HE & 11 & - & - & - & - & - \\
\hline $\begin{array}{l}\text { Plantago tomentosa Gilib. } \\
\text { PIPERACEAE }\end{array}$ & HE & - & 11 & - & - & - & - \\
\hline $\begin{array}{l}\text { Peperômia catharinae Miq. } \\
\text { POACEAE }\end{array}$ & $\mathrm{EP}$ & 07 & - & - & - & - & - \\
\hline Hymenachne amplexicaulis (Rudge) Nees & HE & 11 & - & - & - & - & - \\
\hline Panicum glutinosum $\mathrm{Sw}$. & $\mathrm{HE}$ & - & 07 & - & - & - & - \\
\hline Polypogon elongatus H. B. \& K. & $\mathrm{HE}$ & 11 & - & - & - & - & - \\
\hline
\end{tabular}




\begin{tabular}{|c|c|c|c|c|c|c|c|}
\hline Schizachyrium condensatum Nees & $\mathrm{HE}$ & 06 & - & - & - & - & - \\
\hline $\begin{array}{l}\text { Setaria parviflora (Poir.) Kerguélen } \\
\text { POLYGALACEAE }\end{array}$ & $\mathrm{HE}$ & 06 & 06 & - & - & - & - \\
\hline $\begin{array}{l}\text { Polygala lancifolia A. St.-Hil. } \\
\text { POLYGONACEAE }\end{array}$ & $\mathrm{HE}$ & 07, 08, 09 & 09 & - & - & - & - \\
\hline $\begin{array}{l}\text { Polygonum acuminatum M. Martens \& } \\
\text { Galeotti }\end{array}$ & $\mathrm{HE}$ & 12 & 12 & - & - & - & - \\
\hline Polygonum hydropiperoides Michx. & $\mathrm{HE}$ & 12 & - & - & - & - & - \\
\hline Polygonum stelligerum Cham. & $\mathrm{HE}$ & 03 & - & - & - & - & - \\
\hline $\begin{array}{l}\text { Rumex obtusifolius L. } \\
\text { ROSACEAE }\end{array}$ & $\mathrm{HE}$ & 11 & 11 & - & - & - & - \\
\hline Prunus sellowii Koehne & AV & - & - & 24,0 & 63,9 & 5 & 14 \\
\hline $\begin{array}{l}\text { Rubus brasiliensis } \text { Mart. } \\
\text { RUBIACEAE }\end{array}$ & $\mathrm{HE}$ & 08 & 08,09 & - & - & - & - \\
\hline Coussarea contracta Benth. \& Hook. f. & $\mathrm{AB}$ & 11 & 06 & 18,9 & 40,5 & 4 & 12 \\
\hline Diodia saponariifolia K. Schum. & $\mathrm{HE}$ & 12 & - & - & - & - & - \\
\hline Guettarda uruguensis Cham. \& Schltdl. & $\mathrm{AV}$ & 11,12 & $01,02,03$ & 32,9 & 50,4 & 5 & 8 \\
\hline Palicourea australis C. M. Taylor & $\mathrm{AB}$ & - & - & - & - & - & - \\
\hline Psychotria carthagenensis Jacq. & $\mathrm{AB}$ & 12 & $\begin{array}{l}03,06,08 \\
09\end{array}$ & - & - & - & - \\
\hline $\begin{array}{l}\text { Rudgea parquioides (Cham.) Müll. Arg. } \\
\text { RUTACEAE }\end{array}$ & $\mathrm{AB}$ & 11 & - & - & - & - & - \\
\hline $\begin{array}{l}\text { Zanthoxylum rhoifolium Lam.* } \\
\text { SALICACEAE }\end{array}$ & $\mathrm{AV}$ & - & - & - & 16,1 & - & 5 \\
\hline Casearia decandra Jacq. & $\mathrm{AV}$ & 07, 08, 09 & - & 19,0 & 47,0 & 4 & 10 \\
\hline Casearia lasiophylla Eichler* & $\mathrm{AB}$ & - & - & - & - & - & - \\
\hline Casearia sylvestris $\mathrm{Sw}$. & AV & 09 & - & - & 17,5 & - & 5 \\
\hline $\begin{array}{l}\text { Salix humboldtiana Willd. } \\
\text { SAPINDACEAE }\end{array}$ & AV & 08 & - & 20,8 & 67,5 & 4 & 12 \\
\hline Allophylus edulis Radlk. ex Warm. & $\mathrm{AB}$ & 08 & - & 21,7 & 35,6 & 5 & 6 \\
\hline Cupania vernalis Cambess.* & $\mathrm{AB}$ & - & - & - & - & - & - \\
\hline $\begin{array}{l}\text { Matayba elaeagnoides Radlk. } \\
\text { SCROPHULARIACEAE }\end{array}$ & AV & 09 & - & 16,6 & 140,1 & 6 & 18 \\
\hline $\begin{array}{l}\text { Buddleja brasiliensis J. Jacq. } \\
\text { SMILACACEAE }\end{array}$ & $\mathrm{HE}$ & $06,07,08$ & - & - & - & - & - \\
\hline $\begin{array}{l}\text { Smilax campestris Griseb. } \\
\text { SOLANACEAE }\end{array}$ & ES & 08 & 03 & - & - & - & - \\
\hline Cestrum bracteatum Link \& Otto & $\mathrm{HE}$ & 08 & - & - & - & - & - \\
\hline Cestrum corymbosum Schltdl. & ES & 08,10 & - & - & - & - & - \\
\hline Solanum aculeatissimum Jacq. & $\mathrm{HE}$ & - & 07 & - & - & - & - \\
\hline Solanum americanum Mill. & $\mathrm{HE}$ & $06,09,10$ & $06,09,12$ & - & - & - & - \\
\hline Solanum flaccidum Vell. & ES & 11 & - & - & - & - & - \\
\hline Solanum laxum Royle & ES & 09 & 09 & - & - & - & - \\
\hline Solanum megalochiton Mart. & $\mathrm{HE}$ & 07,08 & - & - & - & - & - \\
\hline Solanum pseudocapsicum L. & $\mathrm{HE}$ & 09 & 11 & - & - & - & - \\
\hline $\begin{array}{l}\text { Solanum variabile Mart. } \\
\text { SYMPLOCACEAE }\end{array}$ & $\mathrm{HE}$ & 09,11 & - & - & - & - & - \\
\hline $\begin{array}{l}\text { Symplocos uniflora Benth. } \\
\text { THYMELAEACEAE }\end{array}$ & $\mathrm{AB}$ & 11 & 12 & - & - & - & - \\
\hline $\begin{array}{l}\text { Daphnopsis racemosa Griseb. } \\
\text { VERBENACEAE }\end{array}$ & $\mathrm{AB}$ & 08 & 09 & - & - & - & - \\
\hline $\begin{array}{l}\text { Verbena bonariensis L. } \\
\text { WINTERACEAE }\end{array}$ & $\mathrm{HE}$ & 11,12 & - & - & - & - & - \\
\hline Drimys brasiliensis Miers* & AV & - & - & - & 36 & - & 8 \\
\hline
\end{tabular}


Dentre as espécies coletadas, Araucaria angustifolia, Cyperus giganteus e Hypericum carinatum são consideradas raras pela lista vermelha de espécies ameaçadas de extinção no estado do Paraná (HATSCHBACH; ZILLER, 1995). Conforme a lista apresentada por IBAMA (1992), a Araucaria angustifolia é tratada, em nível nacional, como espécie vulnerável à extinção.

A formação florestal estudada se mostrou estruturada em três estratos (superior, médio e inferior). Dentre os indivíduos amostrados, a altura máxima foi de $25 \mathrm{~m}$ e a mínima $1,5 \mathrm{~m}$. O dossel estrato com maior facilidade de definição - variou entre 18 e 25 metros, com destaque para Matayba elaeagnoides, Araucaria angustifolia e Luehea divaricata. Embora Sebastiania commersoniana seja a espécie com maior presença, aparece nesse estrato com poucos indivíduos.

O estrato médio foi caracterizado por exemplares que apresentaram altura entre oito e 17 metros, sendo o estrato mais denso. Neste, Sebastiania commersoniana apresentou expressiva presença, acompanhada de exemplares de Vitex megapotamica e Salix humboldtiana.

No estrato inferior (sub-bosque) encontraram-se indivíduos entre um e sete metros de altura, com maior representatividade novamente para Sebastiania commersoniana, Schinus terebinthifolius, Calyptranthes concinna e Guettarda uruguensis. A cobertura arbustivo-herbácea é muito expressiva, com destaque para Daphnopsis racemosa, Psychotria carthagenensis e Symplocos uniflora, além de indivíduos de Poaceae, Cyperaceae e Pteridophyta, e fungos das divisões Basidiomycota e Ascomycota.

Alguns trabalhos de mesma ordem podem ser citados, como Silva et al. (1997), que realizaram um levantamento florístico em área de várzea do rio Iguaçu, no município de São Mateus do Sul (PR), e Moro (2001), que analisou a estrutura de um fragmento de floresta aluvial no rio Cará-Cará, Ponta Grossa (PR). Comparando os resultados obtidos com os dessas pesquisas, evidenciou-se que a presença de uma maior quantidade de espécies das famílias Asteraceae, Myrtaceae, Solanaceae e Euphorbiaceae segue praticamente um padrão florístico para essa formação florestal.

Os indivíduos arbóreos do presente estudo pertencem a 41 espécies, distribuídos em 20 famílias. Esses resultados, se comparados a outros estudos realizados também no rio Iguaçu por Silva et al. (1997), com 21 famílias, Barddal et al. (2003b) na região de Araucária, com 16, e Iurk et al. (2007) em Balsa Nova, com 14, demonstram que esse número de famílias segue também um padrão. Na tabela 2 são apresentados esses resultados tabulados de maneira comparativa.

Tabela 2. Espécies arbóreas coletadas em Floresta Ombrófila Mista Aluvial no estado do Paraná, nos municípios de Palmeira, São Mateus do Sul, Araucária e Balsa Nova.

Table 2. Collected tree species in aluvial forests in the State of the Paraná, in the counties Palmeira, São Mateus do Sul, Araucária and Balsa Nova.

\begin{tabular}{lcccc}
\hline Estudo & $\begin{array}{c}\text { Palmeira } \\
\text { (este estudo) }\end{array}$ & $\begin{array}{c}\text { São Mateus do Sul } \\
\text { Silva } \text { et al. } \text { (1997) }\end{array}$ & $\begin{array}{c}\text { Araucária } \\
\text { Barddal } \text { et al. (2003b) }\end{array}$ & $\begin{array}{c}\text { Balsa Nova } \\
\text { Iurk } \text { et al. } \text { (2007) }\end{array}$ \\
\hline $\mathrm{N}^{\circ}$ famílias & 20 & 21 & 16 & 14 \\
$\mathrm{~N}^{\circ}$ gêneros & 33 & 26 & 27 & 15 \\
$\mathrm{~N}^{\circ}$ espécies & 41 & 29 & 28 & 21 \\
\hline
\end{tabular}

Sebastiania commersoniana ocorreu nas quatro áreas consideradas nessa comparação. Essa situação pode ser atribuída à grande facilidade de regeneração dessa espécie, que mesmo sofrendo sucessivos desbastes consegue reconstituir-se. Além desse fato, caso indivíduos da espécie venham a cair sobre o solo encharcado, eles têm a capacidade de emitir brotações a partir do tronco principal, formando, então, extensos aglomerados com predominância dessa espécie.

Em todos os meses foram observados indivíduos com floração ou frutificação ou ainda ambas ocorrendo simultaneamente no mesmo indivíduo. De acordo com Ducke (1949), os frutos, quando maduros, arrebentam-se e as sementes são lançadas a distância das respectivas matrizes, sendo a dispersão dessa espécie classificada como autocórica, em que a disseminação de sementes é feita pela própria planta (PIJL, 1982). Essa especificidade contribui ainda mais para o predomínio da espécie.

Das espécies arbustivas, foram encontradas nove famílias. Esses resultados assemelham-se aos de Silva et al. (1997), que registraram a ocorrência de sete famílias, e aos de Barddal et al. (2003a), com apenas quatro. Na tabela 3, esses dados podem ser observados. Apenas Daphnopsis racemosa Griseb. ocorreu nas três áreas. 
Tabela 3. Espécies arbustivas coletadas em Floresta Ombrófila Mista Aluvial do rio Iguaçu, nos municípios de Palmeira (PR), São Mateus do Sul (PR) e Araucária (PR).

Table 3. Collected shrub species in aluvial forest of the Iguaçu river, in the counties of Palmeira (PR), São Mateus do Sul (PR) and Araucária (PR).

\begin{tabular}{lccc}
\hline Estudo & Palmeira & São Mateus do Sul & Araucária \\
\hline $\mathrm{N}^{\circ}$ famílias & 9 & 7 & 4 \\
$\mathrm{~N}^{\circ}$ gêneros & 13 & 9 & 4 \\
$\mathrm{~N}^{\mathrm{o}}$ espécies & 13 & 10 & 4 \\
\hline
\end{tabular}

O estrato arbustivo-herbáceo pode ser considerado como vegetação secundária, por apresentar espécies que se instalam em áreas degradadas pela derrubada da floresta. Nesse ambiente, encontram-se, principalmente, espécies herbáceas consideradas daninhas, invasoras ou ruderais, como Alternanthera philoxeroides, Senecio brasiliensis, Ipomoea indivisa e Rumex obtusifolius, além de espécies que não são nativas do estado do Paraná, como Ludwigia elegans e Ludwigia peruviana. Essas espécies recebem essa denominação por surgirem espontaneamente após completa derrubada das árvores, ou por invadirem terrenos abandonados, formando a cobertura localmente denominada de "tiguera".

A família Asteraceae foi a que apresentou o maior número de espécies herbáceas, sendo 10 no total, seguida por Cyperaceae e Solanaceae com seis cada uma, Poaceae com cinco, Polygonaceae com quatro, Amaranthaceae com três, Commelinaceae, Hypericaceae, Malvaceae, Onagraceae e Phyllanthaceae com duas, e as demais com apenas uma espécie cada. Quando esses resultados são comparados com os de Silva et al. (1997), observa-se que na região de Palmeira foi encontrado um número muito maior de espécies herbáceas (Tabela 4). Pfaffia glomerata, Begonia cucullata, Hypericum brasiliense, Phyllanthus caroliniensis e Polygonum acuminatum ocorreram nas duas áreas, e todas são consideradas daninhas ou invasoras.

Tabela 4. Espécies herbáceas coletadas em floresta aluvial no rio Iguaçu, municípios de Palmeira (PR) e São Mateus do Sul (PR).

Table 4. Collected herb species in aluvial forest in the Iguaçu river, counties of Palmeira (PR) and São Mateus do Sul (PR).

\begin{tabular}{lcc}
\hline Estudo & Palmeira & São Mateus do Sul \\
\hline $\mathrm{N}^{\circ}$ famílias & 26 & 10 \\
$\mathrm{~N}^{\circ}$ gêneros & 46 & 12 \\
$\mathrm{~N}^{\circ}$ espécies & 58 & 12 \\
\hline
\end{tabular}

Parte dos troncos das árvores apresenta-se coberto por espífitas vasculares, representadas principalmente por pteridófitas, Bromeliaceae (4), Cactaceae (2), Orchidaceae (2) e Piperaceae (1). Esse resultado pode ser considerado baixo, se comparado com formações florestais mais úmidas (KERSTEN e SILVA, 2001). A presença de maior umidade no ambiente contribui para o desenvolvimento de espécies epífitas.

No entanto, em trabalhos semelhantes, em áreas de Floresta Ombrófila Mista, como os estudos de Silva et al. (1997) e Kersten e Silva (2002), os números de famílias se assemelham (Tabela 5). Aechmea recurvata, Platyaechmea distichantha, Tillandsia tenuifolia, Tillandsia usneoides e Leptotes unicolor são espécies bastante comuns na região e ocorreram nas três áreas de estudo. Esse comportamento parece seguir um padrão para áreas com estágio de desenvolvimento menor, com diversidade e riqueza dos estratos arbóreos bem inferiores, influenciando diretamente no comportamento das espécies escandentes.

As espécies escandentes coletadas na área estão distribuídas em sete famílias, dentre as quais Solanaceae apresentou três espécies, Asteraceae duas e as demais apenas uma. Esses dados, se comparados com Silva et al. (1997), são muito semelhantes, ocorrendo um número reduzido de espécies por família (Tabela 6). Tragia volubilis e Passiflora misera foram as únicas que ocorreram nos dois estudos. 
Tabela 5. Espécies epífitas coletadas em floresta aluvial no estado do Paraná, nos municípios de Palmeira, São Mateus do Sul e Araucária.

Table 5. Collected epiphytes species in aluvial forest in the State of the Paraná, the counties of Palmeira, São Mateus do Sul and Araucária.

\begin{tabular}{lcc}
\hline Estudo & Palmeira & São Mateus do Sul \\
\hline $\mathrm{N}^{\circ}$ famílias & 8 & 11 \\
$\mathrm{~N}^{\circ}$ gêneros & 10 & 15 \\
$\mathrm{~N}^{\circ}$ espécies & 11 & 16 \\
\hline
\end{tabular}

Tabela 6. Espécies escandentes coletadas em floresta aluvial do rio Iguaçu, no estado do Paraná, nos municípios de Palmeira e São Mateus do Sul.

Table 6. Collected lianes species in aluvial forest of the Iguaçu river, in the State of the Paraná, the counties of Palmeira and São Mateus do Sul.

\begin{tabular}{lccc}
\hline Estudo & Palmeira & São Mateus do Sul & Curitiba \\
\hline $\mathrm{N}^{\circ}$ famílias & 5 & 4 & 5 \\
$\mathrm{~N}^{\circ}$ gêneros & 10 & 13 & 18 \\
$\mathrm{~N}^{\circ}$ espécies & 12 & 18 & 30 \\
\hline
\end{tabular}

\section{CONCLUSÕES E RECOMENDAÇÕES}

Foram levantados 318 indivíduos, distribuídos em 67 famílias, 111 gêneros e 134 espécies, sendo 40 espécies arbóreas, 14 arbustivas, 57 herbáceas, 12 epífitas e 11 escandentes. As famílias que mais se destacaram por apresentar maior número de espécies foram Myrtaceae (13), Asteraceae (13), Solanaceae (9), Cyperaceae (6), Rubiaceae (6), Bromeliaceae (5) e Poaceae (5).

Sebastiania commersoniana foi a espécie dominante em ambos os compartimentos, confirmando, pela comparação com outras áreas de floresta aluvial no Paraná, sua alta adaptabilidade e eficiência de colonização.

Espécies ruderais e exóticas foram encontradas, provavelmente, pelo fato de a área avaliada estar bastante sujeita a ação antrópica, que promove abertura de clareiras com a derrubada de árvores, vindo a favorecer o aparecimento das espécies mencionadas. Também deve se levar em conta que determinadas espécies de comportamento arbóreo ou arbustivo terão sua presença dificultada por apresentar concorrência com essas herbáceas.

Com este trabalho detectou-se a presença de espécies vulneráveis à extinção. Isso evidencia a real necessidade da realização de outros levantamentos florísticos, a fim de fomentar e subsidiar programas de preservação e recuperação desses ambientes, por hora tão antropizados. Dessa maneira, poderá ser minimizada essa frequente perda de recursos naturais, contribuindo-se assim para a conservação dessas espécies, sem comprometer as gerações presentes e futuras.

\section{REFERÊNCIAS}

AB'SABER, A N. O suporte ecológico das florestas beiradeiras (ciliares) In: RODRIGUES, R. R.; LEITÃO FILHO, H. DE F. (eds.). Matas Ciliares: conservação e recuperação. 2. ed. São Paulo: Editora da Universidade de São Paulo: Fapesp, 2001. p. 15 - 25.

APG. An update of the Angiosperm Phylogeny Group classification for the orders and families of flowering plants: APG II. Linnaean Society. Botanical Journal, London, v. 141, p. 399 - 436. 2003.

BARDDAL, M. L.; RODERJAN, C. V.; GALVÃO, F.; CURCIO, G. R. Fitossociologia do sub-bosque de uma Floresta Ombrófla Mista Aluvial, no município de Araucária, PR. Ciência Florestal, Santa Maria, v. 14, n. 1, p. 35 - 45, 2003 a.

BARDDAL, M. L.; RODERJAN, C. V.; GALVÃO, F.; CURCIO, G. R. Caracterização florística e fitossociológica de um trecho sazonalmente inundável de floresta aluvial, em Araucária, PR. Ciência Florestal, Santa Maria, v. 14, n. 2, p. 37 - 50, 2003b. 
BONNET, A. Caracterização fitossociologica das bromeliáceas epifíticas e suas relações com os fatores geomorfológicos e pedológicos da planície do rio Iguaçu, Paraná, Brasil. $350 \mathrm{f}$. Tese (Doutorado em Engenharia Florestal) - Setor de Ciências Agrárias, Universidade Federal do Paraná, Curitiba, 2006..

BORGHI, W. A.; MARTINS, S. S.; DEL QUIQUI, E. M.; NANNI, M. R. Caracterização e avaliação da mata ciliar à montana hidrelétrica de Rosana, na Estação Ecológica do Caiuá, Diamante do Norte, PR. Cadernos da Biodiversidade, Curitiba, v. 4, n. 2, p. 9 - 18, 2004.

BRASIL. Lei $\mathrm{n}^{\circ}$ 4.771, de 15 de setembro de 1965. Institui o Novo Código Florestal. Diário Oficial da União. Brasília, 15 de setembro, 1965.

BRUMMIT, R. K.; POWELL, C. E. Authors of plant names. Kew: The Royal Botanic Gardens, 1992. $732 \mathrm{p}$.

CURCIO, G. R. Caracterização geológica, pedológica e fitossociológica do rio Iguaçu, Paraná, Brasil.. 500 f. Tese (Doutorado em Engenharia Florestal) - Setor de Ciências Agrárias, Universidade Federal do Paraná, Curitiba, 2006.

DUCKE, A. Árvores brasileiras e sua propagação. Boletim Museu do Paraense Emílio Goeldi, Belém, v.10, p. $81-92.1949$.

DURIGAN, G.; RODRIGUES, R. R.; SCHIAVINI, I. A heterogeneidade ambiental definido a metodologia de amostragem da floresta ciliar. In: RODRIGUES, R. R.; LEITÃO FILHO, H. DE F. (Eds.). Matas Ciliares: conservação e recuperação. 2. ed. São Paulo: Editora da Universidade de São Paulo: Fapesp, 2001. p. $159-167$.

FELFILI, J. M.; SILVA-JUNIOR, M. C. Floristic composition, phytosociology and comparison of cerrado and gallery forest at Fazenda Água Limpa, Federal District, Brazil. In: FURLEY, P. A., PROCTOR, J.; RATTER, J. A. (Eds.). Nature and dynamics of forest-savana boundaries. London: Chapnam \& Hall, 1992. p. 392-416.

FIDALGO, O.; BONONI, V. L. R. Técnicas de coleta, preservação e herborização de material botânico. São Paulo: Instituto de Botânica, 1989. (Manual n. 4).

HATSCHBACH, G. H.; ZILLER, S. R. Lista vermelha de plantas ameaçadas de extinção no Estado do Paraná. Curitiba: SEMA/GTZ, 1995. 139 p.

INSTITUTO BRASILEIRO DE GEOGRAFIA E ESTATÍSTICA (IBGE). Manual Técnico da Vegetação brasileira. Departamento de Recursos Naturais e Estudos Ambientais. Rio de Janeiro, 1992. 92 p. (Manuais técnicos em Geociências, n. 1).

INSTITUTO BRASILEIRO DO MEIO AMBIENTE E DOS RECURSOS NATURAIS RENOVÁVEIS (IBAMA). Portaria no 37-N, de 3 de abril de 1992, torna pública a Lista Oficial de Espécies da Flora Brasileira Ameaçada de Extinção. Disponível http://www.cetesb.sp.gov.br/licenciamentoo/legislacao/federal/portarias/1992_Port_IBAMA_37.pdf. Acesso em: 25/08/2007.

INTERNATIONAL PLANT NAME INDEX (IPNI). Disponível através do site: <http://www.ipni.org.> Acesso em: 25/08/2007.

IURK, M. C.; ZACARIAS, R. R.; SAVI, M.; KARVAT, S. G.; GOMES, G. S.; PACHECHENIK, P. E.; GALVÃO, F.; RODERJAN, C. V. Levantamento florístico e fitossociológico de um trecho de floresta ciliar do rio Iguaçu, município de Balsa Nova - PR. Ambiência, Guarapuava, 11 p, 2007. No prelo.

KERSTEN, R. A. SILVA, S. M. Florística e estrutura do componente epifítico vascular em Floresta Ombrófila Mista Aluvial do rio Barigüi, Paraná, Brasil. Revista Brasileira de Botânica, São Paulo, v. 25 , n. 3, p. $259-267$, set. 2002.

KERSTEN, R. A.; SILVA, S. M. Composição florística e distribuição espacial de espífitas vasculares em floresta da planície litorânea da Ilha do Mel, Paraná, Brasil. Revista Brasileira de Botânica, São Paulo, v. 24, p. $213-226,2001$. 
KLEIN, R. M. Aspectos dinâmicos da vegetação do sul do Brasil. Sellowia, Itajaí, v. 36, n. 36, p. 5 - 54, 1984.

LIMA, W. P. Função hidrológica da mata ciliar. In: SIMPÓSIO SOBRE MATA CILIAR. Anais... Campinas: Fundação Cargil, 1989. p. 25 - 42.

MAACK, R. Geografia Física do Estado do Paraná. 3. ed. Curitiba: Imprensa Oficial, 2002. 438 p.

MATTEUCCI, S. D.; COLMA, A. Metodologia para el estúdio de la vegetacion. Washington: OEA/PRDCT, 1982. $168 \mathrm{p}$.

Melo, M. S., MORO, R. S., Guimarẽes, G. B. Patrimônio Natural dos Campos Gerais do Paraná. Ponta Grossa: UEPG, 2008. 288 p.

MELO, M. S.; MENEGUZZO, I. S. Patrimônio natural dos Campos Gerais do Paraná. In: DITZEL, C. H. M.; LÖWEN SAHR, C. L. Espaço e Cultura: Ponta Grossa e os Campos Gerais. Ponta Grossa: Editora da UEPG, 2001. p. 415-428.

MORO, R. S.; SMITH, J.; DIEDRICHS, L. A. Estrutura de um fragmento da mata ciliar do rio CaráCará, Ponta Grossa, PR. Publication UEPG, Ponta Grossa, v. 1, n. 1, p. 19-38, 2001.

PARANÁ. Secretaria Municipal do Meio-Ambiente. Coletânea de Legislação Ambiental, 2. ed. Curitiba: IAP/GTZ, 1996.

PASDIORA, A. L. Florística e fitossociologia de um trecho de floresta ripária em dois compartimentos ambientais do rio Iguaçu, Paraná, Brasil. 48 f. Dissertação (Mestrado em Engenharia Florestal) - Setor de Ciências Agrárias, Universidade Federal do Paraná, Curitiba, 2003.

PIJL, L.V.D. Principles of dispersal in higher plants. 2. ed. New York: Springer Verlag, 1982. 211 p.

REICHARDT, K. Relações água-solo-planta em mata ciliar. In: SIMPÓSIO SOBRE MATA CILIAR. Anais... Campinas: Fundação Cargil, 1989. p. 20 - 24.

RODRIGUES, R. R. Análise estrutural das formações florestais ripárias. In: SIMPÓSIO SOBRE MATA CILIAR. Anais... Campinas: Fundação Cargil, 1989. p. 99 - 119.

RODRIGUES, R. R. Florestas ciliares? Uma discussão nomenclatural das formações ciliares. In: RODRIGUES, R. R.; LEITÃO FILHO, H. DE F. (Eds.). Matas Ciliares: conservação e recuperação. 2. ed. São Paulo: Editora da Universidade de São Paulo: Fapesp, 2001. p. 91 - 108.

RODRIGUES, R. R.; SHEPHERD, G. J.; Fatores condicionantes da vegetação ciliar. In: RODRIGUES, R. R.; LEITÃ̃ FILHO, H. DE F. (Eds.). Matas Ciliares: conservação e recuperação. 2. ed. São Paulo: Editora da Universidade de São Paulo: Fapesp, 2001. p. 101 - 108.

RODRIGUES, R. R; GANDOLFI, S. Conceitos, tendências e ações para a recuperação de florestas ciliares. In: RODRIGUES, R. R.; LEITÃO FILHO, H. DE F. (Eds.). Matas Ciliares: conservação e recuperação. 2. ed. São Paulo: Editora da Universidade de São Paulo: Fapesp, 2001. p. 235 - 247.

SILVA, S. M.; BRITEZ, R. M.; SOUZA, W. S.; MOTTA, J. T. W. Levantamento florístico em área de várzea do rio Iguaçu, São Mateus do Sul - PR - Brasil. Arquivos de Biologia e Tecnologia, Curitiba, v. 40, n. 4, p. $903-913,1997$.

STEVENS, V.; BACKHOUSE, F.; ERIKSSON, A. Riparian management in British Columbia: an important step towards maintaining biodiversity. British. Columbia: B. C. Ministry of Forests. 1995.

VAN DEN BERG, E. Estudo Florístico e Fitossociológico de uma floresta ripária em Itutinga, MG, e a análise das correlações entre variáveis ambientais e a distribuição das espécies de porte arbóreoarbustivo. 73 p. Dissertação (Mestrado em Engenharia Florestal) - Setor de Ciências Agrárias, Universidade Federal de Lavras, Lavras, 1995.

VELOSO, H. P.; RANGEL FILHO, A. L. R.; LIMA, J. C. A. Classificação da vegetação brasileira adaptada a um sistema universal. Rio de Janeiro: IBGE, 1991. 124 p. 